\title{
Chapter 9 \\ The Presentational Self and Meaning \\ Construction in Our Lives
}

In this concluding chapter, I make a conceptual summary of the presentational self in meaning construction as discussed throughout my exploration, and I attempt to briefly point out its newness for our understanding the self in our lives. Although I constructed my discussion with a focus on the interactions in which children participate, this review takes a wider view to understand the functioning of our minds in general.

Since its beginning, psychology has kept asking study participants, including children, who they are, in various ways. Some asked them about it directly, while others inquired into our thinking with a variety of tasks and inventions. In doing so, we psychologists have been constructing a static understanding of the mind, including our self-representations or self-understanding. We also invoke high scientific purpose as the reason why we must ask these questions. Some of us claim to do that for basic understanding of human nature, while others stress the practical need to save children from undesirable results of development. Psychology always needs rationales for our questioning and understanding of the mind, and we are used to such pairings of reason and result (or understanding). Yet understanding of this kind is a static representation of the self, assumed to exist in individuals as an internal entity, or of personality features with mystical causal properties (e.g., I am shy because of my introversion).

Of course, questions are being asked all the time. Our daily lives are sites where other people ask us many questions, and we also ask questions of others. However, these questions do not necessarily accompany clear intentions; sometimes they stem from serious interest in another's experiences, but some are just killing time before dinner, although this may also function perfectly well in our relationships. Here the absence of any reason paradoxically implies the legitimacy of questioning in our lives. We are asked questions because our lives are the places in which we are permitted to be asked, even though we do not necessarily have to answer. Our lives are the site of dialogical interaction and negotiation that has been constructed throughout history, and we understand each other through these interactions. 
The inquiries in this monograph are the extension of these understandings in daily dialogues made without academic reason. For this reason, the discussion here is not directly related to practical advice that one might use. However, the data shown here exemplify the process by which meaning construction is made and "who children are" becomes clearer in their lives. Although these analyses lack some objectivity in their procedure and do not guarantee reproducibility, they construct a new framework to grasp development, microgenetically and ontogenetically, in relation to the dynamics that require and establish meaning construction.

\section{A Relational View on the Self in Meaning Construction}

To discuss the self and meaning construction in children's lives, I first proposed three fundamental orientations for my inquiries, considering the characteristics of our daily interactions (Chap. 1). These are the focus on continuous dynamics of meaning construction; consideration of the observer who understands what is achieved in the interaction; and the avoidance of over-reliance on reproducibility as an assurance of the findings. None of these fit with the presuppositions of contemporary psychology, but they help figure out the nature of daily lives.

This approach to children's selves resonates with explorations by researchers who were active over 70 years ago. In the development of psychology, there surely was a tradition that tried to understand the emergence of meaning as a presentation in our mind that was constructed from a variety of objects working as a whole (Chap. 2). To understand this process in children's meaning construction, I took the basic framework of the semiotic approach of cultural psychology (Valsiner, 2007, 2017) that attempts to understand the emergence of psychological data as the result of movement of the agencies of meaning construction (i.e., study participants, researchers). The analysis of mother-child conversations in this framework clarified how young children and their mothers elaborate their shared field of meaning relying on the potential of the concepts or proper nouns they introduced into the field, which I described using the dialectic dynamics denoted as $\mathbf{A}<>$ non-A (Chap. 3). It is in this process that the presentational selves of children emerge in our understanding, looking at the interaction.

This approach to the self is different from recent psychological research into the self, which often uses fixed questions to identify self-representation or selfunderstanding presupposed as an internal entity. However, the model of the presentational self insists that the pairs of questions and answers that constitute such pseudo-scientific reports are one subtype of the dialogues that enable the emergence of the presentational self, although awkwardly perverted and restricted (Chap. 4). In other words, the self is somehow appearing in every dialogue we participate in, even when we say nothing about our experiences.

My approach has focused on how the "I" of the children emerges in interaction, in clear contrast with empirical research in the past that attempted to draw out the 
"I" as something demanded in response to questions posed by researchers. Although a somewhat hackneyed phrase, this suggests the self emerges, totally dependent on the other(ness) that constructs the dialogical relationship. In concrete interactions for meaning construction, there is no generalized other.

\section{Dialogical Process in Meaning Construction and the Emergence of the Self}

The analysis of children's writings as an application of the presentational self concept clarified the role of others in meaning construction in detail through their non-attendance in meaning construction (Chap. 5). Because of the absence of concrete others who collaboratively extend the shared field of meaning on site, children in the third and fourth grades often used stereotyped ways of meaning construction to enumerate events or objects they encountered. However, children also extended these by introducing a variety of dialogues into the process.

These examples also showed how the self becomes clearer for a person who describes his or her experiences. This involves multiple types of dialogical relationships with others, which differ depending on how conversation is achieved. In these dynamics, the child who writes his or her personal stories is also able to find the self in the result of meaning construction, presumably clearer than in conversation, which is not accompanied by visible traces.

The others appearing in meaning construction have distinctive roles. The importance of self-other comparison or interpersonal relationships in the construction of the self has already been pointed out in existing research. In addition to these discussions, current analyses have showed that others work powerfully as promoters of meaning construction that potentially drive a variety of extensions of meaning (e.g., Excerpt 3.2), or to trigger the child's strong reactions and give him or her clearer focus on details (e.g., Excerpt 5.6). Thus, the emergence of the presentational self always accompanies dialogue with others, and this process has its foundation in the structure of our lives.

\section{Dynamics of Daily Lives that Enable Meaning Construction}

Once we understand these dialogical processes, the question that remains is how these processes occur, proceed, and re-occur in our lives. This question was not asked in existing psychological studies, because these basically involve researchers posing questions to participants, or otherwise asking participants to talk about something that fits the purpose of the research. 
My inquiry into children's selves first discussed the relationship between reunions in children's lives and their meaning construction. The phenomenon of reunion is ubiquitous in our lives, and it is not just an occasion for casual conversation. As is observable in many well-known procedures in psychology, reunion is deeply related to the functioning of our minds and depends on two types of dialectic tension in our lives: visible $<>$ invisible and same $<>$ non-same. It is difficult for us to control or predict how reunion is achieved, but these dialectic tensions are the keys to further understanding the process (Chap. 6).

The dialectic tension concerning visibility is related to both the physical and social construction of the world we live in. Basically, we have a tendency to identify the hidden both by our movements in the physical world and by semiotic extensions, yet we are somehow ambivalent in our relationship with invisibility. As is clear from history, we need invisibility because we need to construct ourselves by making something else visible to us (Chap. 7). On the other hand, the tension of same $<>$ non-same is a latent dynamic that enables development in the area of similarity (Chap. 8). Although this study focused on the microgenesis of meaning, this perspective suggests inquiries into a wide range of developments occurring in the fluctuations of our actions.

\section{The Indivisibility of Relationship, Meaning Construction, and the Self}

Ever since the definition of the self by James (1890), inquiries of psychology have presupposed the self to be what exists inside independent persons. Although the theorists of symbolic interactionism considered the roles of others in the emergence of the self (e.g., Mead, 1934), they still described processes attributable to individuals. Harter (1999)'s discussion below suggests the powerful effect of James's perspective on psychology over a century ago, even 20 years after this discussion was made. In other words, most psychological studies of the self can be included in the framework explained here.

In James, therefore, we find many themes that anticipate contemporary issues about the self. First and foremost is the distinction between "I" and "Me" selves, which has become of paramount importance to developmental psychologists. James' multidimensional, hierarchical view of the Me-self has been modernized in recent treatments of the selfstructure, where investigators have sought to examine the particular relationships among global and domain-specific self-evaluations. Moreover, the potential conflict between different Me-selves that James observed has served as a springboard to contemporary interest in the construction of multiple selves. (pp. 16-17)

The discussion in this monograph emphasizes the self in the indivisible complex of relationships, meaning construction and the self, not in individuals. Although existing studies always emphasize the importance of interpersonal relationships that have huge effects on the self, it might even sound contradictory that 
we find the self not in the individual but in relationships. To exemplify this basic conclusion, once more I will introduce the cast of a story written by a great Danish author.

So off went the Emperor in procession under his splendid canopy. Everyone in the streets and the windows said, "Oh, how fine are the Emperor's new clothes! Don't they fit him to perfection? And see his long train!" Nobody would confess that he couldn't see anything, for that would prove him either unfit for his position, or a fool. No costume the Emperor had worn before was ever such a complete success.

"But he hasn't got anything on," a little child said.

"Did you ever hear such innocent prattle?" said its father. And one person whispered to another what the child had said, "He hasn't anything on. A child says he hasn't anything on."

"But he hasn't got anything on!" the whole town cried out at last.

The Emperor shivered, for he suspected they were right. But he thought, "This procession has got to go on." So he walked more proudly than ever, as his noblemen held high the train that wasn't there at all.

(transl. Jean Hersholt $)^{1}$

The context is filled with the tension of visibility and invisibility. As I discussed in Chap. 7, almost everyone attempts to see the new clothes to befit his or her position (i.e., the construction of their selves). They are constructing relationships with the object and the Emperor and thus becoming obedient servants or good, clever citizens. In this way, their role or who they are in society is closely related to the meaning construction. However, the child who reveals the deception best exemplifies my discussion. Perhaps in a dialogue with his or her father, the child constructs a new meaning in relation to what was observed. Though the father tries to exercise his power by framing this as "innocent prattle," thus attempting to position his child as one who knows nothing, the meaning construction clarifies the child's uniqueness both in relation to others (i.e., the adults around the child) and what is observed.

The self here appears in the meaning construction and in the relationships, and we find it. If we could interview the child about what he or she thinks about his or her self, it is quite plausible that the child would not mention innocence or honesty, at least prior to the event. If the child was to make the same comments while watching the broadcast of the procession on television, assuming such a thing existed, the ultimate end would be different, because the meaning construction would be made and would function in an environment distant from the site. Accordingly, the child's presentational self is not what the child describes about the self, nor something that constantly and stably exists inside the child, but rather what we find in the meaning construction in context and in the configuration of persons and objects as a result of the meaning construction.

\footnotetext{
${ }^{1}$ Retrieved from http://www.andersen.sdu.dk/vaerk/hersholt/TheEmperorsNewClothes_e.html
} 
The story also describes the same $<>$ non-same tension and development. From an objective viewpoint, the procession is almost the same until the end of the story. The Emperor also keeps his self-understanding as an emperor. However, the child's meaning construction has changed what the procession may lead to: from the rise of the Emperor's authority to the undermining of it. In a world that seeks to maintain its sameness, some meaning construction clarifies the self in relationships and can also trigger huge developments.

As the final point, this monograph itself is an act of presentational self, in which you find my self. In my efforts to find out how to give new meaning to the concept of the self, I went through a wide range of conversations with theories and empirical evidence. Yet I surely know that the Emperor's procession keeps going on. Or maybe not?

Open Access This chapter is licensed under the terms of the Creative Commons Attribution 4.0 International License (http://creativecommons.org/licenses/by/4.0/), which permits use, sharing, adaptation, distribution and reproduction in any medium or format, as long as you give appropriate credit to the original author(s) and the source, provide a link to the Creative Commons license and indicate if changes were made.

The images or other third party material in this chapter are included in the chapter's Creative Commons license, unless indicated otherwise in a credit line to the material. If material is not included in the chapter's Creative Commons license and your intended use is not permitted by statutory regulation or exceeds the permitted use, you will need to obtain permission directly from the copyright holder.

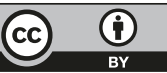

